\title{
O EFEITO DE TERCEIRA PESSOA: UMA REVISÃO TEÓRICA ${ }^{1}$
}

\author{
Rachel Callai Bragatto ${ }^{2}$
}

\begin{abstract}
Resumo
Tendo em vista o grande avanço nos estudos acerca do efeito de terceira pessoa e o seu reconhecimento como um "membro venerável da família dos conceitos sobre os quais os pesquisadores de comunicações de massas regularmente se debruçam" (PERLOFF, 1999, p. 354), este artigo busca fazer uma revisão dos mecanismos que estão por trás deste fenômeno. Revê as pesquisas acerca dos componentes perceptivo e comportamental e também sobre os principais mediadores do efeito, a saber, desejabilidade e distância social. Pretende, desta forma, colaborar para um mapeamento do campo de forma a subsidiar estudos posteriores.
\end{abstract}

Palavras-chave: teorias da comunicação; teorias da recepção; efeito da terceira pessoa, media effects.

\begin{abstract}
Considering the major breakthrough on the research about the third-person effect and its recognition as a "a venerable member of the family of concepts that mass communications scholars regularly adressed" (Perloff, 1999, p. 354), this article aims to review the mechanisms behind this phenomenon. Revise the studies on the perceptual and behavioral components and also on the main predictors of the effect, namely, desirability and social distance. Therefore intends to contribute to the field mapping and to further studies agenda.
\end{abstract}

Keywords: communication theory; reception studies; third-person effect; media effects.

\section{Resume}

Teniendo en cuenta el gran avance en la investigación sobre el efecto de tercera persona y su reconocimiento como "un miembro venerable de la familia de conceptos a que los estudiosos de comunicación masiva se comprometen con regularidad" (Perloff, 1999, p. 354), este artículo tiene como objetivo revisar los mecanismos que subyacen a este fenómeno. Revisa los estudios sobre los componentes de la percepción y de comportamiento, y también sobre los principales factores predictivos del efecto, es decir, la deseabilidad y la distancia social. Por lo tanto, tiene la intención de contribuir a la cartografía del campo y a la agenda de investigación.

Palabras-clave: teoría de la comunicación; estudios de recepción; efecto de tercera persona; efectos de los media.

\section{A HIPÓTESE DO EFEITO DA TERCEIRA PESSOA E SUAS IMPLICAÇÕES INICIAIS}

Partindo de algumas experiências pessoais e de relatos históricos que sugeriam a pequena persuasão direta da propaganda e dos meios de comunicação em geral e, em contraposição, uma percepção dos observadores que as outras pessoas seriam mais vulneráveis que eles à influência das mensagens midiáticas, Davison (1983) estabelece uma conceitualização que mais tarde abriria um amplo leque de estudos no campo dos media effects: a hipótese do efeito da terceira pessoa. Para o autor, uma pessoa exposta a uma mensagem

\footnotetext{
${ }^{1}$ DOI deste artigo: $10.5380 /$ recp.v6i2.41426.

${ }^{2}$ Doutoranda em Sociologia na Universidade Federal do Paraná (UFPR). Faz parte do grupo de pesquisa Instituições, Comportamento Político e Novas Tecnologias (GEIST) da mesma universidade. Realizou estágio de doutoramento na Universidade da Califórnia - Los Angeles (UCLA). Bolsista Capes. E-mail: rachelbragatto@gmail.com.
} 
dos meios de comunicação tende a acreditar que os outros sofrerão mais influência da mensagem que ela mesma e, por conta dessa expectativa da influência nos demais, o indivíduo pode ser compelido à ação.

In its broadest formulation, this hypothesis predicts that people will tend to overestimate the influence that mass communications have on the attitudes and behavior of others. More specifically, individuals who are members of an audience that is exposed to a persuasive communication (whether or not this communication is intended to be persuasive) will expect the communication to have a greater effect on others than on themselves. And whether or not this individuals are among the ostensible audience for the message, the impact that they expect this communication to have on others may lead them to take some action (DAVISON, 1983, p. 3).

De acordo com a hipótese, os efeitos seriam consequências das ações daqueles que antecipam a reação do público e que, como resultado, comportam-se de maneira diferente. Uma suposição chave do conceito é que percepções do impacto da mídia no eu e nos outros são entidades distintas, isto é, os indivíduos separam em suas mentes a percepção do efeito da comunicação no eu e nos outros (PERLOFF, 1999).

A mensuração desta discrepância é geralmente feita por meio de experimento com a exposição dos indivíduos a uma mensagem e posterior preenchimento de um formulário pedindo estimativas dos efeitos no eu e nos outros. Além disso, em alguns estudos os participantes fazem estimativas do impacto de um tipo de mídia em especial e não de uma mensagem.

O título, efeito da terceira pessoa, seria adequado por duas razões. Do ponto de vista daqueles que avaliam os efeitos da comunicação, haveria um maior impacto das mensagens nos outros (terceira pessoa) que neles mesmos. Já do ponto de vista dos comunicadores e propagandistas, aqueles (terceira pessoa) preocupados com as atitudes e comportamentos da audiência deveriam ser os persuadidos, procurando manipulá-los como se estivessem, aparentemente, direcionando as mensagens para outras pessoas.

As principais implicações desse estudo inicial dizem respeito à percepção de políticos e religiosos, por exemplo, da má influência que determinados tipos de mensagens podem ter no seu público, criando dissenso e questionamento. A constante reclamação de governantes a respeito da influência da cobertura midiática na percepção geral dos eleitores, seria mostra da adequação da hipótese. Quanto ao aspecto comportamental, Davison relaciona o efeito da terceira pessoa (ETP) ao apoio a atitudes censoras, já que, enquanto o censor acredita nunca ser influenciado, os outros seriam suscetíveis às mensagens e, portanto, 
não deveriam entrar em contato com elas. Portanto, o debate sobre a regulamentação de conteúdo midiático seria, em certa medida, influenciado pelos achados que a hipótese apresenta. No entanto, cabem aqui observações que serão exploradas na conclusão desse artigo.

Dentre as noções já levantadas em estudos prévios e que interagem com o efeito da terceira pessoa, Davison elenca a ideia de que os especialistas superestimariam o efeito da mídia sobre os leigos, enquanto subestimariam o impacto sobre si mesmos, justificando-o por meio do seu acesso a fontes mais seguras. $\mathrm{O}$ autor pondera que, de certa maneira, todos nós seríamos especialistas nos assuntos que nos importam e que pressupomos que as outras pessoas não saberiam o que sabemos e estariam, portanto, mais suscetíveis aos efeitos das mensagens midiáticas ${ }^{3}$.

Outra explanação trazida pelo autor, e que também abrirá um terreno fértil para pesquisas futuras, diz respeito a uma percepção de parcialidade da mídia, conhecida como hostile media effects. Enquanto os eleitores do candidato A entendem que determinado meio de comunicação tem uma cobertura a favor do candidato B, os eleitores do candidato B acham que o contrário ocorre. De acordo com esta premissa, cada observador assume que um efeito desproporcional será alcançado por meio de mensagens midiáticas apoiando o lado oposto ao seu. O público (terceira pessoa) será impressionado por estes argumentos ou fatos, pois não teria a informação que torna o observador apto a formular uma opinião "correta". Gunther et al (2001) e Gunther e Christen (2002) exploraram este conceito em estudos sobre a percepção acerca da opinião pública, ligando-o a outros conceitos como a ignorância plural (FIELDS e SCHUMAN, 1976) e a hipótese da espiral do silêncio (NOELLE-NEUMANN, 1974).

De modo geral, Davison demonstra ainda outras questões ligadas à hipótese chave, como a do efeito reverso ou da primeira pessoa (quando o observador julga que a mensagem tem mais influência sobre ele que sobre os demais); da desejabilidade social (quando uma mensagem é vista como boa e desejável pelo observador, pode ocorrer o efeito reverso) e da distância social (influência da proximidade social e da identificação do observador com os grupos de comparação).

\footnotetext{
${ }^{3}$ Para um estudo mais recente a respeito da relação entre especialistas e ETP, ver Huh e Langteau, 2007.
} 
De acordo com Perloff (1999), seriam moderadores do efeito de terceira pessoa a desejabilidade do conteúdo da mensagem, a distância social entre si e outros e características entre indivíduos e grupos. A cultura também é um fator esperado como moderador por alguns pesquisadores, conforme demonstram Lee e Tamborini (2005) em estudo comparativo entre culturas coletivistas e individualistas sobre pornografia na internet.

Nos últimos anos muito se avançou na pesquisa sobre o efeito de terceira pessoa, com a publicação frequente de artigos em periódicos internacionais. O conceito estimulou análises nos mais variados campos, desde a psicologia social até a comunicação política. Portanto, como tentativa de sistematização da pesquisa recente sobre esta hipótese, os estudos revisados daqui por diante serão organizados de acordo com algumas das noçõeschave apresentadas. O objetivo é agrupá-los de forma a mapear os achados anteriores e apontar possíveis questões ainda não respondidas.

Primeiramente, far-se-á a distinção entre o componente perceptivo e o comportamental da hipótese, explicitando com artigos os caminhos e as grandes questões da pesquisa. Em seguida, serão exploradas duas noções predictors, isto é, variáveis tratadas pelos autores como mediadores do efeito da terceira pessoa e que podem estar presentes em estudos que tratam tanto do componente perceptivo quanto do comportamental. Opta-se pela distância social e desejabilidade social, pois, além de serem as variáveis mediadoras mais exploradas justamente pela forte relação com o efeito da terceira pessoa, estão intimamente ligadas a outras noções, como a do efeito reverso, por exemplo.

\section{COMPONENTE PERCEPTIVO E COMPONENTE COMPORTAMENTAL}

Dois componentes do efeito de terceira pessoa são identificados pelos pesquisadores (SALWEN e DRISCOLL, 1997; PERLOFF, 1993; SALWEN, 1998): o perceptivo, no qual os indivíduos percebem as mensagens midiáticas como tendo maior impacto nos outros que neles mesmos (percepção de terceira pessoa) e o comportamental, ou seja, esta percepção leva a mudanças de comportamento como apoio à censura de determinados conteúdos.

Em artigo revisando a hipótese do efeito de terceira pessoa, Perloff (1999) afirma que todas as pesquisas até aquele momento haviam confirmado a distorção entre a percepção dos efeitos no eu e nos outros. Portanto, não haveria dúvida que a percepção alterada do impacto ocorre quando os indivíduos julgam o efeito de uma mensagem mediada nos outros e no eu. 
Diversos autores (BROSIUS e ENGELS, 1996; DUCK et al, 1999; PERLOFF, 1993) mostraram que as pessoas tendem a se ver sob uma luz mais positiva que os outros, identificando que o efeito seria motivado por um senso de preservação da autoestima, chegando ao ponto de um otimismo irreal ao comparar o eu ao outro. Nesse sentido, quando confrontado com mensagens julgadas negativas, o indivíduo tenderia a perceber uma maior influência sobre o outro que sobre o eu - resultado da proteção ou alargamento do ego (egoenhancement). Porém, quando o contrário ocorre, isto é, o participante é exposto a um conteúdo positivo, tende a perceber-se como mais influenciado que os demais - resultado também do mesmo princípio.

De acordo com Lambe e McLeod, "ego-enhancement theory suggests that we will see others as being more affected by undesirable media messages. Bolstering this line of reasoning, some studies demonstrate that the third-person perception is attenuated for desirable messages, sometimes even reversed" (2005, p. 278).

Henriksen e Flora (1999) confirmam esta afirmação em um estudo analisando o efeito da terceira pessoa em crianças. Eles descobriram que enquanto as crianças acreditavam que seus pares seriam mais influenciados por propagandas pró-cigarro que elas mesmas, com as mensagens antifumo ocorreria o oposto, isto é, teriam mais impacto sobre elas mesmas que sobre os demais.

De acordo com estas prerrogativas, Peiser e Peter (2000) procuraram expandir a aplicação do ETP para além das mensagens midiáticas: propuseram-se a analisar o impacto presumido do uso da mídia, isto é, ao invés de utilizarem determinados conteúdos midiáticos como estímulo, buscaram verificar qual a percepção dos participantes acerca da influência do hábito de assistir televisão em geral. Coerente com os achados anteriores, a pesquisa mostra que o efeito de terceira pessoa ocorre também nesta situação, de modo que os autores sugerem que o fenômeno não está restrito ao campo dos media effects. Para eles, de modo geral a percepção social seria positiva para o eu e negativa para os outros. "People quite generally tend toward unrealistically positive perceptions of the self and toward unrealistically negative perceptions of the others" (PEISER e PETER, 2000, p. 40).

Em estudo seguinte, os mesmos autores testam um possível constrangimento do efeito de terceira pessoa, a saber, características individuais pertinentes a percepção social em questão. Estes fatores influenciariam a magnitude do efeito de terceira pessoa. Por exemplo, os que assistem menos televisão, sentiriam-se em melhor condição para perceber que os 
outros são mais influenciados por anúncios publicitários que eles mesmos (PEISER e PETER, 2001). Os achados demonstram que as características individuais ou circunstanciais tendem a afetar mais diretamente as percepções sobre o eu que sobre os outros. Uma importante contribuição deste trabalho é a conclusão de que não apenas questões motivacionais estão por trás do efeito de terceira pessoa, mas também fatores circunstanciais, características individuais e conhecimento, especialmente sobre si mesmo.

Outras razões para o fenômeno, como o Erro de Atribuição Fundamental (Fundamental Attribution Error) e a Hipótese da Exposição (Exposure Hypothesis), também foram analisadas por pesquisadores. De acordo com a noção do Erro de Atribuição Fundamental (GUNTHER, 1991), os indivíduos usam diferentes critérios para inferir as causas do seu comportamento e do comportamento dos outros. Especificamente, em contextos negativos, os indivíduos tendem a incluir fatores mais complexos ao explicar o seu comportamento, enquanto descontam tais fatores ao avaliar o comportamento dos demais. Portanto, ao presumir o impacto da mídia nos outros, os indivíduos fazem uso de um modelo simples, como se exposição fosse igual a influência. Porém, quando pensam no impacto sobre si mesmos, incluem outros fatores que podem mediar o efeito.

Partindo dessa compreensão, McLeod et al (2001) buscam identificar o locus do impacto, isto é, se e como a influência presumida ocorre no eu, no outro ou em ambos. Trabalhando com quatro variáveis (exposição presumida, natureza antissocial do conteúdo, atitudes paternalísticas e senso comum) relacionam todas elas à discrepância entre o efeito percebido no eu e nos outros, porém com os antecedentes impactando de forma distinta cada uma das partes.

For others, the primary predictor of perceived impact is exposure, as would be expected from a direct effects model of media influence such as the magic bullet theory. For the self, on the other hand, the nature of the media content and common sense are important contingent that are taken into account, whereas simple exposure is seen as irrelevant in assessments of media impact (MCLEOD et al 2001 p. 691).

Já na Hipótese da Exposição, a percepção do efeito seria resultado da suposição do indivíduo acerca de sua exposição e da exposição dos outros às mensagens midiáticas. Supondo, por exemplo, que os demais estão mais expostos ao conteúdo midiático, eles seriam, portanto, mais influenciados. Eveland e seus colegas (1999) testaram experimentalmente a hipótese: enquanto o grupo de controle respondeu ao questionário padrão, o grupo experimental preencheu um formulário no qual o participante deveria pressupor que tanto ele quanto os demais haviam sido expostos ao mesmo tempo de mídia. 
No entanto, como não houve diferença significativa nos efeitos presumidos, indica-se que há outros constrangimentos além dos fatores evidenciados pela Hipótese da Exposição.

Em outro artigo sobre os mecanismos por trás do ETP, Reid e Hogg (2005) buscam na Teoria da Categorização Própria (Self-Categorization Theory) explicações para o fenômeno. De acordo com esta teoria, quando uma categoria ou identidade social comum a um grupo são evidentes psicologicamente, as pessoas identificam elas mesmas e os outros em termos das características definidas do grupo (protótipo ou norma). Por meio desta ideia, pode-se prever que o efeito de terceira pessoa será acentuado se a identidade social tiver destaque, se o outro não pertencer ao grupo e se a mídia for percebida como um fator normativo para os outros. Entretanto, se a mídia for normativa para o grupo, ocorre o efeito reverso. Através de três estudos, os autores chegam à conclusão de que os achados são coerentes com a teoria da categorização e que elucidariam melhor o efeito da terceira pessoa, embora até então a noção de alargamento do ego tenha se difundido como a mais elucidativa do efeito da terceira pessoa (PERLOFF, 2002 apud REID e HOGG, 2005).

Não obstante ainda haja muito espaço para análises e questões a serem respondidas acerca do componente perceptivo, nos últimos anos foi o componente comportamental que tem recebido mais atenção. Já no seu artigo pioneiro, Davison enfatizou o potencial de consequências comportamentais do efeito da terceira pessoa, especialmente em relação à ação social estratégica, exemplificando com questões relacionadas à economia (ações e comércio de bens) e à censura de materiais midiáticos. Notou que mesmo que as mensagens não produzam efeito real nas audiências isto pode não ter importância, pois grande parte do público tende a acreditar que os demais foram influenciados. O impacto público esperado pode motivar as pessoas à ação.

The phenomenon of censorship offers what is perhaps the most interesting field for speculation about the role of the third-person effect. Insofar as faith and morals are concerned, at least, it is difficult to find a censor who will admit to having been adversely affected by the information whose dissemination is to be prohibited. Even the censor's friends are usually safe from the pollution. It is the general public that must be protected. Or else, it is youthful members of the general public, or those with impressionable minds (DAVISON, 1983, p. 14).

O fator comportamental seria, portanto, um dos aspectos mais intrigantes do efeito da terceira pessoa. Agentes responsáveis por políticas públicas, por exemplo, agem baseados na percepção de que a opinião pública é influenciada pela mídia. O poder da mídia estaria 
justamente na percepção de sua possível influência e no entendimento de que o público pode ser influenciado.

Nesse sentido, os estudos sobre o componente comportamental analisam, especificamente, os vários antecedentes relacionados ao juízo acerca do impacto da mídia nos outros e no eu e sua consequente relação com a censura. Atitudes que apoiam a censura são importantes objetos de pesquisa porque permitem ou encorajam os políticos a implementar restrições para o conteúdo midiático (MCLEOD et al, 2001).

Desta forma, vários estudos demonstraram que o fator comportamental do efeito de terceira pessoa é fundamental para prever o apoio dos indivíduos à restrição de conteúdos midiáticos como violência na TV (HOFFNER et al, 2001; HOFFNER et al, 1999), letras de rap (EVELAND E MCLEOD, 1999) e pornografia (WU e KOO, 2001).

Chia et al (2004) investigaram a percepção da terceira pessoa e as motivações por trás do apoio à censura tendo como pano de fundo um vídeo compact disc não autorizado que expunha a vida sexual de uma política da Tailândia. De acordo com os autores, embora outros estudos já tenham explorado as explicações preventiva ${ }^{4}$ (proteger os outros dos efeitos danosos da comunicação) e punitiva (compensar o sujeito da mensagem negativa e punir a mídia por meio de restrições) para o apoio à censura, nenhum fez com ambas simultaneamente. Os achados sugerem que o apoio à censura é fruto da penalização da mídia por prejudicar intencionalmente o sujeito da mensagem. A explicação preventiva foi parcialmente confirmada, pois somente o efeito percebido no eu e não nos outros foi considerado predictor do apoio à censura. Além disso, concluíram que a censura era apoiada não apenas como restrição governamental - os indivíduos também se recusavam a disseminar o conteúdo quando o consideravam danoso.

Em uma pesquisa de 1999, Hoffner et al analisam o apoio à censura de mensagens violentas na televisão. Coerente com achados anteriores, os resultados demonstram que quão mais frequente é a exposição, menor a predisposição à censura - o público deste tipo de programa tende a se sentir menos perturbado pelo conteúdo e a analisá-lo como menos danoso. No entanto, ao contrário da pesquisa de Chia et al (2004), para os respondentes o conteúdo televisivo violento aumentaria as tendências agressivas nos outros e a percepção de mundo cruel no eu. Isto é consistente com a visão de que a restrição de conteúdo é motivada pelo desejo de proteger a sociedade (explicação preventiva), não importando tanto

\footnotetext{
${ }^{4}$ Chamada por outros autores de atitude paternalista, como em McLeod et al 2001.
} 
o impacto presumido no eu, mas sim nos outros. Gênero e idade também moderariam o efeito, sendo que as mulheres e as pessoas mais velhas teriam maior tendência a apoiar a censura.

Por sua vez, Price et al (1998) propõem que o impacto sobre o eu, mais do que o sobre os outros, influencia na decisão das pessoas de darem suporte ou não à publicação da mensagem. Utilizando para o estudo uma matéria jornalística de negação do holocausto, os autores demonstram que mais do que consultar alguma noção abstrata de como os outros reagiriam ao anúncio, os participantes parecem usar uma medida mais acessível e confiável: eles mesmos. Os resultados sugerem que as percepções de terceira pessoa podem não levar a censura através da oposição a mensagens danosas, mas sim através de valores mais pessoais e do julgamento de veracidade da mensagem.

Percebe-se certo consenso entre os achados quanto ao fato dos indivíduos tenderem a apoiar a censura de conteúdos potencialmente desviantes, ainda que não haja acordo quanto às razões que os levem a isso, sendo apontadas desde explicações punitivas (CHIA et al, 2004), passando por motivos preventivos (HOFFNER et al, 1999) e chegando a justificativas baseadas no eu e em avaliações particulares. Mas o que ocorre quando o conteúdo das mensagens não é necessariamente antissocial, como campanhas políticas ou processos jurídicos?

Ao invés dos tradicionais experimentos com mensagens negativas, Salwen e Driscoll (1997) e Salwen (1998) analisam as restrições ao conteúdo midiático no contexto do julgamento de O.J. Simpson e das eleições presidenciais americanas de 1996, respectivamente. Os resultados indicam que o efeito de terceira pessoa pode contribuir para a compreensão do apoio a restrições, mesmo se o assunto é visto como legítimo para o processo democrático. Porém, o ETP não parece ser central quando temas relativos à democracia estão em jogo. Sugerem, portanto, que os estudiosos dediquem-se a entender por que os indivíduos apoiam a censura e, especificamente, deixem de presumir a legitimidade de um assunto e questionem a percepção de legitimidade do público. "They need to investigate whether individuals perceive issues as legitimate and, if so, whether perceived issue legitimacy affects the third-person process" (SALWEN, 1998, p. 274-275).

Procurando responder algumas dessas perguntas, Salwen e Dupagne (1999) analisaram o impacto da influência da mídia e de seus efeitos imorais nas percepções individuais sobre três temas. A restrição ao conteúdo mostrou-se dependente do assunto. Para a violência televisiva, o tema com a mais clara dimensão moral, os efeitos imorais percebidos funcionaram como predictor do apoio à censura. Porém, a percepção da influência 
geral da mídia foi um fator chave para as restrições de notícias sobre julgamentos e anúncios políticos negativos. Ao distinguir essas duas dimensões dos efeitos percebidos, clareiam fatores por trás do ETP.

Mas nem só de censura vive o componente comportamental do efeito de terceira pessoa. Gunther e Storey (2003) apresentam o papel da influência presumida, modelo estendido do ETP no qual as pessoas percebem o efeito de uma mensagem nos outros e reagem a esta percepção (para os autores, ao contrário da hipótese da terceira pessoa, este modelo não prevê uma distinção perceptiva entre o eu e os outros e nem foca em mensagens de cunho antissocial, por isso seria mais amplo). Tendo como contexto uma campanha radiofônica dirigida à saúde materna no Nepal, investigam o impacto da comunicação na audiência indireta de um programa de rádio, isto é, como um grupo que não é o alvo da mensagem reage a ela.

The data support an indirect model summarized by the following steps. One, people in the general client population observe and attend to the contend of an information campaign, even though they are not part of the target audience. Two, these people anticipate influence of the information campaign on the target audience, the clinic health workers, and a corresponding change in these same health workers. Three, these perceptions of change lead people to develop more positive expectations about the professional qualities of health workers. Four, as a result of theses expectations, people form more positive attitutes toward health workers. Finally, more positive attitudes cause the client group to perceive (and perhaps even contribute to) more positive and productive clienthealth worker interactions and to feel more confident about their own efficacy in dealing with health workers (GUNTHER E STOREY, 2003, p. 211-212).

Um possível problema desta pesquisa é a relação causal: a percepção da influência positiva do programa de rádio levou a uma melhor imagem dos trabalhadores ou uma imagem positiva dos trabalhadores levou os clientes a percebê-los como mais influenciados pelo programa?

Estendendo o componente comportamental para o domínio demográfico, um estudo de Tsfati e Cohen (2003) comprovou a influência da cobertura midiática sobre cidades periféricas israelenses nas percepções de seus moradores e consequente desejo de mudar-se, independente das condições objetivas do local. Este trabalho é emblemático ao demonstrar que mesmo a respeito de temas relacionados com a identidade própria, nossa percepção sobre o que os outros pensam é fundamental. As percepções de terceira pessoa moldam, portanto, também como nos sentimos em relação a nossa vida e podem levar as pessoas à ação. 
Nesta mesma linha, tendo em vista o ambiente social e também econômico, Tewksbury et al (2004) demonstraram que a crença de que as outras pessoas são particularmente vulneráveis às mensagens da mídia contribuiu com as intenções individuais de armazenar suplementos como forma de se preparar para o bug do milênio. Assinalam que a ansiedade por conta das mensagens noticiosas e a crença que os demais iriam super estocar bens, fez com que os participantes preocupassem-se com o armazenamento de água, comida, dinheiro e gasolina.

Com este breve panorama acerca dos componentes perceptivo e comportamental do efeito, fica evidenciado o impacto do efeito da terceira pessoa. Atitudes censoras, comportamentos relativos a serviços públicos, migrações demográficas e questões econômicas são influenciadas pelo ETP e o estudo do fenômeno é fundamental. Portanto, na próxima sessão serão explorados dois moderadores do efeito da terceira pessoa, intimamente ligados entre si, e frequentes na maioria dos estudos sobre o tema.

\section{DESEJABILIDADE E DISTÂNCIA SOCIAL}

A desejabilidade social das mensagens, compreendida como a predisposição do indivíduo de se permitir ser influenciado por conteúdo midiático, é considerada uma forte variável do efeito de terceira pessoa. Desta forma, via de regra, a magnitude do efeito aumentaria ou diminuiria de acordo com a valência da mensagem. Para conteúdo negativo, antissocial ou desviante, maior o ETP. Para mensagens positivas, pró-sociais ou não desviantes, menor o ETP, podendo até mesmo ocorrer o efeito reverso, também conhecido como de primeira pessoa. Nesse sentido, Eveland et al (1999) verificaram que quando a mensagem é negativa, a tendência é que os respondentes não se vejam atrelados a ela e nem os seus próximos. Porém, os outros seriam significativamente afetados.

David e Johnson (1998) verificaram os efeitos de mensagens sobre a imagem corporal feminina de acordo com vários níveis de indesejabilidade. Demonstraram uma hierarquia que vai dos efeitos midiáticos mais fracos, que afetam a percepção de peso corporal ideal, aos mais indesejáveis, chegando a manifestações de distúrbios alimentares. De acordo com o aumento da indesejabilidade social, constataram uma queda brusca nos efeitos percebidos no eu, enquanto apenas um declínio moderado nos efeitos percebidos nos outros. Observaram, portanto, que a magnitude do efeito aumentava junto com a indesejabilidade da mensagem. 
Procurando ampliar o campo, Henriksen e Flora (1999) questionaram se as crianças percebem uniformemente impacto maior das mensagens sobre os demais do que sobre eles mesmos ou se há alguma conexão com o tipo da mensagem. Comprovaram que elas pressupunham que os anúncios publicitários de cigarro (conteúdo antissocial) têm mais influência nos demais que nelas mesmas, sendo que o contrário ocorreu em relação às campanhas anti-fumo (conteúdo pró-social), caracterizando o efeito reverso. Além disso, o efeito reverso parece ser maior nas crianças mais velhas.

Uma possível explicação para a moderação da distância social do ETP é dada por Duck et al (1999). "In the interests of self-presentation, people may be motivated to perceive themselves as relatively responsive to intelligent and beneficial messages- that is, they may display a reverse third-person effect in which self is perceived as more, rather than less influenced than others" (p. 1880). Está, em grande medida, relacionada, portanto, à noção de alargamento do ego.

Willnat et al (2002) trabalharam com a percepção das audiências europeias e asiáticas acerca do efeito da mídia norte-americana, especificamente, conteúdo violento. As compreensões sobre o impacto do conteúdo midiático estadunidense variaram de acordo com os valores culturais, políticos e sociais locais, assim como com a noção de ganho de conhecimento. Enquanto os europeus, que avaliavam negativamente a influência americana, demonstraram um grande efeito de terceira pessoa, os asiáticos, que julgaram positivo o impacto da mídia, não perceberam os outros como mais influenciados que eles mesmos. Porém, as percepções acerca das mensagens violentas foram comuns, atravessando fronteiras geográficas. Europeus e asiáticos entenderam o conteúdo como negativo e, portanto, previram um impacto maior dos efeitos sobre os outros do que sobre eles mesmos.

Buscando também compreender como as pessoas julgam as mensagens midiáticas, Joslyn (2003) fez uma análise mesclando o efeito de terceira pessoa, o framing (enquadramento) e a desejabilidade da mensagem. Tendo como pano de fundo o escândalo sexual envolvendo o presidente Clinton e a estagiária Mônica Lewinsky, a autora coloca as questões de pesquisa: se o framing é tido como um efetivo agente de mudança para vários juízos políticos, os juízos sobre os efeitos da mídia em si e nos outros acontecem de maneira similar? As considerações destacadas em um enquadramento são utilizadas como base para perceber o impacto da mídia no eu e no público? Usando um framing do caso que evidenciava questões sexuais (mensagem antissocial) e outro que destacava questões éticas e legais (mensagem pró-social), verificou que o impacto sobre o eu foi menor no primeiro 
frame que no segundo e os efeitos de terceira pessoa foram maiores após exposição ao enquadramento sexual. Enquanto a percepção do impacto sobre o eu alterava-se de acordo com o framing, a percepção da influência sobre os outros permanecia constante.

Ainda que possa parecer que tudo são flores no que se refere à desejabilidade social das mensagens e que há consenso em relação à noção, as análises demonstram que há muito a se investigar. Um problema apontado é que a desejabilidade social da mensagem não é medida, mas presumida. A mesma crítica, aliás, enfrentada pelos estudos sobre o impacto comportamental e a censura quanto à legitimidade das mensagens.

De acordo com Eveland e McLeod (1999), a hipótese que mensagens pró-sociais produziriam percepções mais fracas, não existentes ou reversas do efeito da terceira pessoa, se comparadas às mensagens antissociais, não está completamente comprovada. Ao contrário dos achados a respeito do conteúdo midiático antissocial, não há um padrão claro nos resultados relativos às mensagens pró-sociais. Desta forma, trabalhando com canções de rap, os autores comprovaram que tanto a percepção do impacto da mídia no eu quanto nos outros foi significativamente influenciada pela manipulação da desejabilidade da mensagem. Entretanto, a diferença nos efeitos percebidos no eu devido à manipulação da desejabilidade social foi maior que a diferença dos efeitos percebidos nos outros. Para dar conta disto, eles propõem que os pesquisadores tenham em mente: (a) a desejabilidade social de um conteúdo ou gênero específico; (b) a desejabilidade social de ser influenciado por aquele conteúdo ou gênero e (c) a desejabilidade social de ser influenciado pela mídia como um todo.

Perfoff (2002) verificou que o contexto da mensagem e não apenas a desejabilidade moderam os efeitos percebidos. Inspirados nessa pesquisa, Lambe e McLeod (2005) analisaram nove contextos diferentes distribuídos em categorias, usando meios de expressão variados para a comparação de resultados. Os participantes tinham que avaliar o contexto, os efeitos que teriam no eu e nos grupos de comparação e atribuir valores de acordo com a estimativa do efeito. Por fim, deveriam indicar a percepção de exposição (neles e nos outros e para cada tipo de mídia e contexto) e o grau de desejabilidade (mensagem pró-social ou antissocial).

Os resultados contradizem a afirmação de que grande indesejabilidade será refletida em maiores diferenças perceptuais. É provável que a desejabilidade do contexto de uma mensagem interaja com julgamentos sobre a susceptibilidade de uma audiência em particular, determinando assim a amplitude das percepções de terceira pessoa. Nesse sentido, os 
achados sugerem que a relação entre contexto da mensagem e uma audiência em particular pode ser a chave do efeito de terceira pessoa.

Fica clara, portanto, a necessidade de outros estudos que avaliem qual o entendimento prévio dos indivíduos acerca dos temas, em que medida isto influencia sua percepção do efeito da mídia sobre eles mesmos e sobre os outros, a percepção da exposição do eu e dos demais à mensagem e o papel dos grupos de comparação específicos, articulando assim, a desejabilidade e a distância social.

Partimos, portanto, para a outra variável moderadora do ETP, a distância social, que tem sua base nas características individuais, na percepção dos outros e de como se avalia a interação com os demais. O pertencimento a um grupo geraria a comparação social com outros grupos e os efeitos de distanciamento social seriam, portanto, baseados na especificidade ou generalidade do grupo, similaridade ou diferença entre o respondente e o grupo, probabilidade do grupo de comparação estar exposto a certo estímulo e, por fim, visão de si no mundo real (DAVID et al, 2002).

Os estudos demonstram que a distância social pode ser operacionalizada de várias maneiras, como pela generalidade do grupo (BROSIUS e ENGEL, 1996; HENRIKSEN e FLORA, 1999, HOFFNER et al, 2001), idade (LAMBE e MCLEOD, 2005), raça (DAVID et al, 2002), educação, tamanho (TEWKSBURY, 2002), etc. Perloff (1993) sugere que o fenômeno da distância social tem como base a distância psicológica - grau de similaridade presumida pelo respondente entre ele e o grupo de comparação. Quando os respondentes se identificam com um grupo de comparação, o ETP é atenuado (Duck et al, 1999). Seguindo essa lógica, quando o participante não se identifica com o grupo, o ETP será maior. É o corolário da distância social. Além disso, podem haver grupos particulares de comparação que os respondentes julguem especialmente suscetíveis a um tipo de mensagem (EVELAND et al, 1999; JENSEN e HURLEY, 2005; PRICE et al,1998). Alguns desses exemplos serão analisados com mais detalhes abaixo.

Em estudo já citado no tópico acima, Henriksen e Flora (1999) procuraram também avaliar a mediação da distância social. A influência percebida da mensagem antissocial (anúncio de cigarro) sobre si mesmo e os demais foi menor quando as crianças compararamse aos seus grandes amigos que aos colegas. Da mesma forma, Brosius e Engel (1996) constataram um efeito percebido maior no grupo generalizado que no grupo composto de amigos do respondente. 
Os achados de Hoffner et al (2001) também indicam coerência com o corolário da distância social, isto é, a natureza do grupo de comparação influenciaria o juízo do respondente. Eles demonstraram que o ETP era maior para o grupo de comparação descrito como residentes dos EUA (mais generalizado) do que para os residentes da comunidade local (mais específico). Os autores afirmam que provavelmente os residentes da comunidade local eram percebidos como pessoas que dividiam os mesmos valores e crenças que os respondentes, o que ocorreria em menor escala com os residentes dos EUA. Sugeriram considerar as comparações sociais com uma maior variedade de características e de circunstâncias sociais.

É o que Lambe e McLeod (2005) procuram fazer por meio de um recorte geracional. O critério é dado nesta pesquisa pela diferença de idade entre o participante e dois grupos de comparação em outras faixas etárias (18 a 24 anos e 40 a 50 anos), permitindo que o respondente se identifique com um grupo e não se identifique com o outro. De modo geral, respondentes que se sentiam parte de um grupo pressupunham um efeito maior da mensagem sobre o grupo mais distante do que sobre o grupo ao qual julgava pertencer ou sobre si mesmo.

Já Tewksbury (2002) analisa o impacto das variações de tamanho do grupo de comparação nas percepções do participante. Parte da ideia de que por trás da percepção do impacto sobre os "outros" ocorra uma compreensão que os "outros" são a massa, e ser a massa nunca foi um elogio (comportamento violento, pouca racionalidade, vulnerabilidade à persuasão). Articulando esta noção com a de que qualquer fator que leve o inquirido a exagerar suas percepções de impacto da mídia pode aumentar o suporte popular à censura, pesquisa a possibilidade do suporte à censura ser afetado pela distância social. Seu artigo articula diferentes grupos de comparação (por exemplo, típico grupo de universitários, típico grupo de moradores do estado, típico grupo de americanos) e diferentes tamanhos destes grupos (1, 10 ou 1000 pessoas para cada categoria). O autor demonstra que a estimativa da influência da mídia nos outros aumenta com o tamanho do grupo. Porém, com o tamanho mantido constante, a percepção aumenta à medida que os outros tornam-se mais distantes socialmente ou geograficamente. Desta forma, fica claro que o tamanho do grupo tem influencia sobre os efeitos percebidos. Entretanto, a distância social e o tamanho do grupo seriam variáveis independentes, pois mesmo com o tamanho mantido constante, os respondentes demonstraram uma tendência a estimar maiores efeitos à medida que o outro se torna mais remoto (o mesmo ocorreu na relação inversa - distância constante e o aumento 
do tamanho). Em consequência, o autor sugere considerar o tamanho do grupo como uma variável independente na compreensão de como as pessoas estimam o efeito das mensagens da mídia, pois os respondentes tenderiam a fazer julgamentos mais favoráveis de indivíduos que de agregados de indivíduos.

David et al (2002) colocam outra importante questão. Com a mídia personalizada e segmentada, seria necessário encontrar meios de estudar as relações entre grupos, de dentro e fora deles. Para os autores, o estudo pela via do ETP mostra-se apropriado e viabiliza uma plataforma para o teste das diferenças baseado em identificação social. Em estudos anteriores de efeitos de terceira pessoa, o distanciamento social foi abordado como a distância entre o respondente e o grupo de comparação. A distância entre o respondente e a fonte da mensagem midiática é um outro componente de distanciamento social e o endereçado no artigo. Dessa forma, fazem um estudo de como colegiais brancas e negras percebem os efeitos de anúncios de moda (responsáveis pela construção do imaginário corporal) em si, em pessoas da mesma raça e em pessoas de outra raça. Procuram, portanto, verificar a interação entre a raça da modelo do anúncio, a raça da respondente e a raça do grupo de comparação, considerando identificação e distanciamento sociais como variáveis dentro do recorte da pesquisa. Dois aspectos são considerados: similaridade entre a fonte da mensagem e o respondente e similaridade entre o respondente e o grupo de comparação.

Ao avaliar o ETP sem usar a variável da raça, isto é, procurando analisar o efeito percebido no eu e nos outros, sendo os outros da mesma raça que a respondente, assim como a modelo do anúncio, observou-se o tradicional efeito de terceira pessoa. Ao presumir os efeitos em outras colegiais, negras e brancas indicaram que as outras iriam se identificar apenas com a mesma raça ou com o grupo de modelos de mesma raça. Porém, quando estimaram os efeitos percebidos em si, brancas e negras diferiram. Brancas reportaram não haver diferença no uso de modelos de outras raças, já as negras afirmaram a identidade social do grupo. A grande diferença encontrada foi que as brancas projetaram efeitos no seu grupo iguais quando expostas às modelos negras ou brancas.

When social distance was narrowly defined based on race, the traditionally robust effects of social distance were nullified or reversed. It appears that the participants' perceptions of in-group and out-group norms took precedence over normative social distance defined along racial lines (DAVID et al, 2002, p. 287).

Eveland et al (1999) propuseram que a interação entre contexto da mensagem e grupo de comparação pode influenciar a magnitude do ETP. "People may observe or infer a 
relationship between certain types of media content and certain types of people" (EVERLAND ET AL, 1999, p. 281). Demonstraram que no contexto de músicas de rap e de filmes violentos, juízos acerca da exposição percebida ao conteúdo influenciam as estimativas de impacto da mídia mais que a similaridade percebida do grupo de comparação.

Seguindo este mesmo caminho, o estudo de Jensen e Hurley (2005) examina três dimensões, a influência presumida (como o indivíduo imagina que a mensagem irá influenciar o outro), comportamento presumido (como imaginam que o outro agirá) e intenção comportamental do destinatário (como ele pretende agir e capacidade de ação) sobre a temática do meio ambiente, especificamente, com mensagens relacionadas à regulação de dióxido e à reintrodução do lobo cinza. No que diz respeito à distância social, verificaram a influência presumida e o comportamento presumido para o eu e cinco grupos de comparação (colegas de sala, residentes locais, residentes do estado, ambientalistas e legisladores). Não conseguiram comprovar o corolário da distância social, já que não houve diferença significativa entre alguns grupos de comparação, indicando que as pessoas são capazes de distinguir entre diferentes tipos de influência e as percepções são, portanto, mais tênues do que o previsto em outros estudos e influenciadas por diversos fatores que não apenas a distância social. Se esta explicação está correta, a relevância percebida do assunto para os grupos de comparação pode mediar o impacto da distância social na influência presumida, isto é, a influência presumida da mensagem nos outros pode ser afetada pelo modo como compreende-se que o grupo social perceba a mensagem.

É evidente, portanto, que diversos aspectos e dimensões da distância social já foram testados. Um cuidado que parece fundamental é que as pesquisas futuras perguntem aos participantes em que medida ele percebe que o grupo de comparação está distante socialmente dele. Pode-se operacionalizar tal medida com questões do tipo: "Em que medida você se identifica com, por exemplo, os residentes locais?”, sendo que a escala de resposta poderia ir de "tal qual como eu" até "nem um pouco como eu". Dessa forma, a distância social poderia deixar de ser presumida pelo investigador e passar a ser mensurada pela percepção do inquirido.

\section{CONSIDERAÇÕES FINAIS}

Ao longo dos últimos 32 anos, desde que Davison (1983) cunhou o termo e delimitou a hipótese do efeito de terceira pessoa, muitos estudiosos têm se debruçado sobre o tema. Observa-se que os pesquisadores têm consenso quanto ao impacto do ETP, especialmente 
quanto ao componente perceptivo, procurando examiná-lo nos mais diversos campos da sociedade. Por conta disso, verifica-se a existência de pesquisas acerca de implicações econômicas e demográficas e sobre o impacto em políticas públicas e comportamento censor. No que diz respeito a este último item, foram usados para análise os mais distintos meios (rádio, tv, internet, jornal, letras de música, vídeos games, vídeo compact disc, etc) e os mais diversos temas (violência, pornografia, invasão de privacidade, holocausto, campanhas de saúde pública, campanhas eleitorais, processos judiciais, etc).

Nesse sentido, cabe observar que o ETP tem relação direta com o debate acerca do controle de conteúdo midiático e não necessariamente com o controle de propriedade e a estrutura dos meios de comunicação ${ }^{5}$. Partindo da validade dessa diferenciação, cabe evidenciar que o ETP é um importante elemento para explicar atitudes de apoio ao comportamento censor e que isso tem sido comprovado pela literatura como se demonstrou ao longo do artigo. No entanto, cabem questionamentos se o ETP é o único mecanismo acionado para justificar o controle de conteúdo e em que casos isso ocorre. Há estudos que mostram que o impacto sobre o eu e avaliações individuais e morais sobre a legitimidade de determinado conteúdo são determinantes (CHIA et al, 2004; PRICE et al, 1998). Isso significa que, ainda que ocorra o ETP, ele pode não ser o elemento-chave para explicar o apoio à censura.

Por exemplo, o efeito de terceira pessoa pode ocorrer em relação à propaganda de cigarro ou de bebidas alcoólicas, para ficar em dois exemplos. Mas, ainda que ele ocorra, a razão acionada pelos indivíduos para justificar a censura pode ser outra que não a previsão de maior impacto da comunicação nos outros que nelas mesmas. Justificativas baseadas em conhecimentos científicos ou mesmo senso comum podem ser acionadas, como a relação entre o consumo de tabaco e/ou álcool e inúmeras doenças.

Caberiam então estudos que analisassem quão determinante é o ETP como predictor de apoio à censura, verificando a relação disso com o tipo de conteúdo (propagandístico,

\footnotetext{
${ }^{5}$ A regulação da mídia é um tema tabu na mídia comercial brasileira, pouco explorado e discutido nos meios de comunicação e frequentemente tomado como sinônimo de censura. Embora o debate na academia e nos movimentos sociais não seja novo, a regulamentação em vigor é dispersa, fragmentada e, em grande parte, bastante antiga (o Código Brasileiro de Telecomunicações, ainda que tenha sofrido muitas emendas, é de 1962 e ainda é o principal marco regulatório das telecomunicações e da radiodifusão - uma legislação anacrônica, de quando a TV era em preto e branco, que é utilizada em tempos de convergência tecnológica, mobilidade e TV digital). Desde a Conferência Nacional de Comunicação, em 2009, o governo federal, pressionado pelos movimentos sociais, tem colocado muito timidamente a pauta. Durante a última campanha eleitoral para presidente, Dilma Roussef falou em "regulamentação econômica da mídia" - referindo-se justamente ao controle de propriedade dos meios de comunicação, uma forma de combater o oligopólio e a propriedade cruzada e incentivar a concorrência e a pluralidade de veículos. O debate não avançou muito desde a sua posse.
} 
entretenimento, jornalístico) e questionando abertamente as justificativas apresentadas para a censura. A aferição de que o ETP ocorre não significa que ele seja o único e/ou o mais importante mecanismo a determinar o apoio ao controle de conteúdo. Assim como o ETP não parece ser central para explicar o controle de assuntos relacionados à democracia (SALWEN, 1998), o mesmo pode ocorrer para o comportamento censor em outros temas. Seria necessário também investigar a legitimidade atribuída pelos indivíduos a um assunto para perceber o quanto isso afeta o efeito de terceira pessoa. É possível que o ETP não explique o apoio à censura de todo e qualquer tipo de conteúdo.

Conforme demonstram as pesquisas, em menor ou maior grau estão imbricadas na origem desse processo questões relacionadas ao ego e à autoestima, processos mentais de percepção dos outros, envolvimento com o conteúdo midiático, assim como aspectos culturais, legitimidade da fonte, gênero, raça, idade.

Evidente que o recorte escolhido primou por algumas noções e que outras questões importantes e relacionadas ao ETP não foram devidamente abordadas. Uma delas é ideia da ignorância plural (FIELDS e SCHUMAN, 1976), na qual os indivíduos assumem que estão sozinhos ao manter determinadas expectativas e atitudes, sem saber que outros as têm de maneira privada. Pode haver por parte deste indivíduo solitário a assunção de que os outros passaram por uma verdadeira lavagem cerebral por conta da interferência dos meios de massa.

Percebe-se também que o efeito da terceira pessoa relaciona-se com outras hipóteses do campo do media effects, como a da espiral do silêncio (NOELLE-NEUMANN, 1974), segundo a qual, ao discordar da opinião definida publicamente, ou o indivíduo não explicita o seu pensamento ou se adapta ao dominante. Da mesma maneira, evidenciam-se imbricações com o framing (TUCHMAN, 1978; GITLIN, 1980), noção de que os meios de comunicação constróem os enquadramentos de referência, de acordo com uma estrutura latente de significado que os leitores ou espectadores usam para interpretar e discutir os eventos públicos. Devem ser consideradas também as relações com o priming, processo de ativação de uma pista mental ou associação que pode servir para acionar pensamentos e juízos, e com a hipótese da agenda setting (MCCOMBS e SHAW, 1972), a influência da mídia ao determinar sobre o que pensar, isto é, a agenda pública.

Muito embora haja consenso em torno da legitimidade da hipótese, restam ainda questões a serem elucidadas quanto aos mecanismos que operam o efeito da terceira pessoa 
e as suas variáveis moderadoras. Perloff (1999) indica que os experimentos deveriam ter seu público ampliado, de forma que as pesquisas não tivessem como respondentes apenas estudantes de graduação (como se verifica na maior parte dos estudos e o que permite pouca generalização), mas envolvessem também outros setores da sociedade. O autor menciona ainda que os estudiosos deveriam questionar se, de fato, as pessoas comparam-se a outras ao refletir sobre os efeitos da mídia e, se ela existe, de que natureza é esta comparação.

Além disso, aspectos culturais precisam ser melhor explorados. Será que o efeito ocorre de maneira diversa entre as culturas? No mesmo sentido, mas tendo como base questões educacionais, será que pessoas com um maior grau de educação apresentam os maiores efeitos de terceira pessoa? Ou ainda questões relativas à renda: há variações do efeito entre pobres e ricos? E os moradores do campo, como é que presumem o impacto da mídia sobre si e sobre os demais? Não bastasse isso, a desejabilidade da mensagem assim como a distância social precisam deixar de ser presumidas e passar a ser questionadas aos participantes.

\section{REFERÊNCIAS}

BROSIUS, H.; ENGEL, D.. 1996. The causes of third-person effects: Unrealistic optimism, impersonal impact, or generalized negative attitudes toward media influence? International Journal of Public Opinion Research, v. 8, n. 2, p. 142-162.

CHIA, S. C.; LU, K.; MCLEOD, D. M.. 2004. Sex, Lies, and Video Compact Disc: A Case Study on Third-Person Perception and Motivations for Media Censorship. Communication Research, v. 31, n. 1, p. 109-130.

DAVID, P.; JOHNSON, M. A.. 1998. The Role of Self in Third-Person Effects About Body Image. Journal of Communication, v. 48, n. 4, p. 37-58.

DAVID, P.; MORRISON, G.; JOHNSON, A. M.; ROSS, F.. 2002. Body Image, Race, and Fashion Models: Social Distance and Social Identification in Third-Person Effects. Communication Research, v. 29, n. 3, p. 270-294.

DAVISON, W. P.. 1983. The Third-Person Effect in Communication. Public Opinion Quartely, v. 47 , p. $1-15$.

DUCK, J. M.; HOGG, M. A.; TERRY, D. J.. 1999. Social Identity and Perceptions of Media Persuasion: Are We Always Less influenced Than Others? Journal of Applied Social Psychology, v. 29, n. 9, p. 1879-1899.

EVELAND, W. P. Jr.; NATHANSON, A. I.; DETENBER, B. H.; MCLEOD, D. M.. 1999. Rethinking the social distance corollary: Perceived likelihood of exposure and the thirdperson perception. Communication Research, v. 26, n. 3, p. 275-302. 
EVELAND, W. P.; MCLEOD, D. M.. 1999. The effect of social desirability on perceived media impact: implications for third-person perceptions. International Journal of Public Opinion Research, v. 11, n. 4, p. 315-333.

FIELDS, J. M.; SCHUMAN, H.. Public Beliefs About the Beliefs of the Public. Public Opinion Quarterly, v. 40, p. 427-448.

GITLIN, T.. 1980. The whole world is watching: Mass media in the making \& unmaking of the new left. Berkeley: University of California Press.

GUNTHER, A.. 1991. What We Think Others Think. Communication Research, v. 18, n. 3, p. 355- 372.

GUNTHER, A. C.; CHRISTEN, C. T.. 2002. Projection or Persuasive Press? Contrary Effects of Personal Opinion and Perceived News Coverage on Estimates of Public Opinion. Journal of Communication, v. 52, n. 1, p. 177-195.

GUNTHER, A. C.; CHRISTEN, C. T.; LIEBHART, J. L.; CHIA, S. C.. 2001. Congenial Public, Contrary Press, and Biased Estimates of the Climate of Opinion. Public Opinion Quarterly, v. 65, p. 295-320.

GUNTHER, A. C.; STOREY, D.. 2003. The Influence of Presumed Influence. Journal of Communcation, v. 53, n. 2, p. 199-215.

HENRIKSEN, L.; FLORA, J. A.. 1999. Third-Person Perception and Children: Perceveid Impact of Pro and Anti-Smoking Ads. Communication Research, v. 26, n. 6, p. 643 - 665.

HOFFNER, C.; BUCHANAN, M.; ANDERSON, J. D.; HUBBS, L. A.; KAMIGAKI, S. K.; KOWALCZYK, L.; PASTOREK, A.; PLOTKIN, R. S.; SILBERG; K. J.. 1999. Support for Censorship of Television Violence: The Role of the Third-PersonEffect and News Exposure. Communication Research, v. 26, n. 6, p. 726-742.

HOFFNER, C.; PLOTKIN, R. S.; BUCHANAN, M.; ANDERSON, J. D.; KAMIGAKI, S. K.; HUBBS, L. A.; KOWALCZYK, L.; SILBERG, K. J.; PASTOREK, A.. 2001. The Third-Person Effect in Perceptions of the Influence of the Television Violence. Journal of Communication, v. 51, n. 2, p. 283-299.

HUH, J.; LANGTEAU, R.. 2007. Presumed Influence of DTC Prescription Drug Advertising: Do Experts and Novices Think Differently? Communication Research, v. 34, n. 1, p. $25-52$.

JENSEN, J. D.; HURLEY, R. J.. 2005. Third-Person Effects and the Environment: Social Distance, Social Desiderability, and Presumed Behavior. Journal of Communication, v. 55, n. 2 , p. $242-256$.

JOSLYN, Mark A.. Framing the Lewinsky Affair: Third-Person Judgments by Scandal Frame. Political Psychology, v. 24, n. 4, pp. 829-844, 2003.

LAMBE, J. L.; MCLEOD, D. M.. 2005. Understanding Third-Person Perception Processes: Predicting Perceived Impact on Self and Others for Multiple Expressive Contexts. Journal of Communication, v. 55, n. 2, p. 277-291.

LEE, B.; TAMBORINI, R.. 2005. Third-Person Effect and Internet Pornography: The Influence of Collectivism and Internet Self-Efficacy. Journal of Communication, v. 55, n. 2, p. 292-310. 
MCCOMBS, M. E.; SHAW, D. L.. 1972. The Agenda-Setting Function of Mass Media. Public Opinion Quarterly, v. 36, p. 176-184.

MCLEOD, D. M.; DETENBER, B. H.; EVELAND, W. P.. 2001. Behind the Third-Person Effect: Differentiating Perceptual Processes for Self and Other. Journal of Communication, v. 51, n. 4, p. 678-695.

Noelle-Neumann, E.. 1974. The spiral of silence: A theory of public opinion. Journal of Communication, 24, p. 43-51.

PEISER, W.; PETER, J.. 2000. Third-Person Perception of Television Viewing Bahavior. Journal of Communication, v. 50, n. 1, p. 25-45.

PEISER, W.; PETER, J.. 2001. Explaining Individual Differences in Third-Person Perception: A Limits/Possibilities Perspective. Communication Research, v. 28, n. 2, p. 156-180.

PERLOFF, R. M.. 1993. Third-Person Effect Research 1983-1992. A review and synthesis. International Journal of Public Opinion Research, v. 5, p 167-182.

PERLOFF, R. M.. 1999. The Third-Person Effect: A Critical Review and Synthesis. Media Psychology, v. 1, p. 353-378.

PRICE, V.; TEWKSBURY, D.; HUANG, L.. 1998. Third-Person Effects on Publication of a Holocaust-Denial Advertisement. Journal of Communication, v. 48, n. 2, p. 3-26.

REID, S. A.; HOGG, M. A.. 2005. A Self-Categorization Explanation for the Third-Person Effect. Human Communication Research, v. 31, n. 1, p. 129-161.

SALWEN, M. B.. 1998. Perceptions of Media Influence and Support for Censorship: The Third-Person Effect in the 1996 Presidential Election. Communication Research, v. 25, n. 3, p. 259-285.

SALWEN, M. B.; DRISCOLL, P. D.. 1997. Consequences of third-person perception in support of press restrictions in the O. J. Simpson trial. Journal of Communication, v. 47, n. 2, p. $60-78$.

SALWEN, M. B.; DUPAGNE, M.. 1999. The Third-Person Effect: Perceptions of the Media's Influence and Immoral Consequences. Communication Research, v. 26, n. 5, p. 523-549.

TEWKSBURY, D.. 2002. The Role of Comparison Group Size in the Third-Person Effect. International Jounal of Public Opinion Research, v. 14, n. 3, p. 247 - 263.

TEWKSBURY, D.; MOY, P.; WEIS, D. S.. 2004. Preparations for Y2K: Revisiting the Behavioral Component of the Third-Person Effect. Journal of Communication, v. 54, p. 138155.

TSFATI, Y.; COHEN, J.. 2003. On the Effect of the "Third-Person Effect": Perceived Influence of Media Coverage and Residential Mobility Intentions. Journal of Communication, v. 53 , p. $711-727$.

TUCHMAN, G.. 1978. Making news: A study in the construction of reality. New York: Free Press..

WILLNAT, L.; HE, Z.; TAKESHITA, T.; LÓPEZ-ESCOBAR, E.. 2002. Perceptions of Foreign Media Influence in Asia and Europe: The Third-Person Effect and Media Imperialism. International Journal of Public Opinion Research, v. 14, n. 2, p. 175-192. 
Revista Eletrônica de Ciência Política, vol. 6, n. 2, 2015.

WU, W.; KOO, S. H.. 2001. Perceived Effect of Sexually Explicit Internet Content: The Third. 